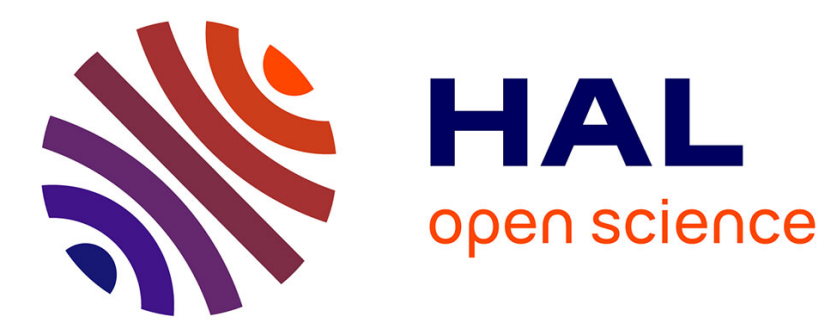

\title{
High temperature corrosion in practical systems
}

John Stringer

\section{To cite this version:}

John Stringer. High temperature corrosion in practical systems. Journal de Physique IV Proceedings, 1993, 03 (C9), pp.C9-43-C9-61. 10.1051/jp4:1993903 . jpa-00252333

\section{HAL Id: jpa-00252333 https://hal.science/jpa-00252333}

Submitted on 1 Jan 1993

HAL is a multi-disciplinary open access archive for the deposit and dissemination of scientific research documents, whether they are published or not. The documents may come from teaching and research institutions in France or abroad, or from public or private research centers.
L'archive ouverte pluridisciplinaire HAL, est destinée au dépôt et à la diffusion de documents scientifiques de niveau recherche, publiés ou non, émanant des établissements d'enseignement et de recherche français ou étrangers, des laboratoires publics ou privés. 


\title{
High temperature corrosion in practical systems (*)
}

\author{
John Stringer
}

EPRI, Palo Alto, California, U.S.A.

\begin{abstract}
There is a wide range of engineering systems where either the efficiency, the cost, or the reliability and lifetime is limited by high temperature corrosion processes. This includes gas turbines, boilers of various kinds, coal gasifiers, reformers and catalytic regenerators in the petrochemical industry, and heat exchangers and heat recovery systems of many kinds. The issues can largely be separated into oxidation and exfoliation, mixed oxidant attack, molten salt accelerated corrosion, and the effect of corrosion on the mechanical properties of the system. The base situation is that a stable protective oxide would normally be formed, and this would be adequate: the role of the other factors is to damage the protective oxide or inhibit its formation. Several practical situations will be described in terms of the processes outlined above.
\end{abstract}

\section{Introduction.}

Materials are required to operate at high temperatures for several different reasons. In energy production systems, the conversion of chemical energy may be achieved by a heat engine, in which the heat of reaction of the fuel, typically reacting with oxygen, is converted first to mechanical energy, by way of a steam or gas turbine, or a reciprocating engine, and then to electrical energy by way of a generator. In a magnetohydrodynamic (MHD) system, the conversion to electricity is achieved by making the combustion gas electrically conducting, and passing it at high velocity through a magnetic field. In a fuel cell, the energy of the chemical reaction is again converted directly to electrical energy, and systems exist for doing this at room temperature. However, there are benefits in using higher-temperature systems. In chemical plant, high temperatures may be required to achieve specific reactions, or to increase reaction rates. In incinerator systems, high temperatures may be required to achieve destruction of potentially harmful species.

The requirements for materials for high temperature applications are that they should perform the required engineering function in a cost-effective way, and this may lead to very different criteria. For example, a rocket engine component may have a design lifetime of the order of 90 minutes; for an industrial gas turbine component, the corresponding requirement may be 20 years. A solution that is economically acceptable for an aircraft gas turbine, because of its lighter weight, may be unacceptable for a land-based engine for which the weight saving does not carry the same economic multipliers in terms of increased payload.

In many cases, indeed in almost all cases, the primary temperature limitation may not be related to corrosion at all. The mechanical requirements may set the maximum permissible temperature. In the case of utility boilers, the strength and corrosion limits are often quite similar, and this may be due to the evolution of the alloy design responding to both requirements.

(*) Primary lecture. 
Because of the problems in developing materials that are capable of satisfying both the mechanical requirements and the corrosion requirements, a systems approach may be adopted, in which a structural material having the necessary mechanical properties is protected from the corrosive environment by a surface treatment or a coating. Generally, a designer prefers to avoid coatings unless the substrate has at least a minimum corrosion resistance. This has been a major problem for the refractory metals, such as niobium: the high-strength alloys have such poor oxidation resistance that the local failure of a protective coating may result in a rapid destruction of the component; in the specifications for research into protective coatings for niobium-based alloys in the early 1960's in the United States, one of the requirements related to the performance of the overall system in the event of a significant coating defect introduce by foreign object damage - the "fly-home capability". Equally, a coating may have to satisfy some mechanical requirements: for example, if the protective coating on a gas turbine blade cracks, the crack may propagate into the substrate and promote its failure.

The understanding of oxidation itself is sufficiently good that simple oxidation is only a problem in some special situations: the performance of refractory metal alloys in advanced aerospace applications in relation to the fly-home capability is one example. Other examples are in chemical plant, where the oxidant may not be oxygen: sulphur boilers are a case in point; carburisation in reformers may be another.

The majority of practical problems are situations where, for some reason, the normal growth of the oxide is disrupted. The consequences may be an acceleration of the corrosion, and an unacceptable rate of section loss; or in some cases there may be a secondary problem: as for example in boilers, where the exfoliating oxide may cause erosion damage to downstream components. Another possible problem is where the inner surfaces of a crack may oxidise, and the volume expansion associated with the oxide growth enhances the crackopening stresses, accelerating mechanical failure.

The problems in practice can mostly be described in terms of four effects:

(1) Exfoliation. This means the macroscopic separation of the major part of a protective scale from the metal surface. This may be an issue in two respects. First, the repeated exfoliation and regrowth of a protective oxide will deplete the substrate in the protective oxide- forming element, and eventually be life-limiting. This is the case in alumina-forming coatings on gas turbine components. The second example is in utility boilers. The oxide scale formed on the inside of the superheater and reheater tubing and piping exfoliates, and the oxide fragments are entrained with the steam, causing severe erosion in the steam valves and the entry stages of the high-pressure and intermediate-pressure steam turbines. Exfoliation can arise for a number of different reasons. First, the metal/oxide interface may be intrinsically strong, but stresses arising from differential thermal expansion may induce either adhesive failure between the oxide and the metal, or cohesive failure in either the oxide or the metal. The intrinsic elastic strains in a large metal structure may exceed the fracture strain of the oxide/metal system: these may in the first instance induce through-scale cracks, but coupled with the differential expansion stresses or the oxide growth stresses, they may then propagate parallel to the interface. Second, the intrinsically strong interface may be weakened, either as a result of the formation of interfacial voids associated with the growth process (the formation of these is a matter of considerable controversy, but that is not a matter for this paper: it is enough to know that such voids do form) or as a result of the segregation of impurities to the interface: currently sulphur is the principal species identified as weakening the interface between $\mathrm{Al}_{2} \mathrm{O}_{3}$ and an alumina-forming alloy, but it 
is known that chlorine and carbon have the same effect, and other elements may also be involved, in a positive or negative sense. Another mechanism leading to spallation is the development of large voids at the interface between the layers of a two-layer scale, even if the two layers are of the same oxide. This leads to spallation of the outer layer, which may not have a great effect on the oxidation rate, but may be important in relation to downstream erosion rates.

(2) Molten salt accelerated oxidation. A molten salt species, such as $\mathrm{V}_{2} \mathrm{O}_{5}, \mathrm{Na}_{2} \mathrm{SO}_{4}$, or $\mathrm{PbO}_{2}$, may deposit on the oxidising surface, and lead to accelerated corrosion. It seems clear that an important step is the disruption of the protective oxide, and it is probable that there are two ways in which this can happen. One way is that described in the previous section: a constituent of the salt may be able to migrate to the oxide/metal interface, and weaken the boundary. The second method is that the salt may dissolve the protective scale. After the protective scale has been destroyed, the corrosion accelerates, and the propagation stage may also involve the molten salt in two ways: the first is simply a continuation of the dissolution process, leading to a precipitation of the oxide in a non-protective form within or outside the molten salt layer; the second involves the salt dissociating to generate a high concentration of a second oxidant; the deleterious effect of this is the subject of the next section. One aspect of molten salt enhanced corrosion that is sometimes neglected is that in practice the salt arrives continuously, and is removed more or less continuously, as the scale spalls or the deposit is removed by some cleaning process or as a result of high-velocity gas flows over the surface, as is the case in a gas turbine.

(3) Second oxidant effect. A second oxidant, such as sulphur or carbon, in amounts insufficient for the protective oxide to become unstable, may nevertheless diffuse into the metal, reacting with the protective oxide-forming element, and, under some circumstances, making it unavailable for maintaining the external protective oxide. There are at least two ways that this may happen. The most extreme is that in some cases the second oxidant may form a phase which is molten which results in a catastrophic breakdown of the metal. This is unusual outside the laboratory. More commonly, the second oxidant reacts with the element responsible for forming the external protective oxide. This in itself may not result in accelerated attack, or indeed reduce the ability of the alloy to form an external protective scale. The important step involves the second oxidant making the element unavailable for external oxide formation, and this can result if, for example, the internal product of the reaction of the oxide-forming element with the second oxidant then oxidises in situ, forming internal oxide; this locks the element, and prevents the formation of an external protective oxide. This has been termed the development of a "critical microstructure" [1].

(4) The interaction of mechanical and corrosion effects. One obvious effect has been mentioned above. In gas turbines, a primary mode of failure of nozzle guide vanes is thermomechanical fatigue: both the stress and the temperature of the airfoil fluctuate in a complex fashion during the start up and shut down cycle, and different parts of the vane experience different conditions. Eventually, a crack is initiated, and propagates, usually fairly slowly, eventually leading to failure of the vane. If the inner surface of the crack 
oxidises, the response of the component to the cycle is modified, because the ability of the crack to close is limited by the oxide. The effect of this is to accelerate failure. Another example is the removal of the oxide forming element from the surface layers of a component. This will clearly affect the mechanical properties of the surface layer, and may promote the initiation of failure. The dissolution of oxygen or nitrogen in the substrate can be an important effect, particularly in titanium alloys, or in the case of nitrogen, high chromium alloys. Carbon dissolution may also be deleterious. The diffusion of elements into the substrate from protective oxides may also modify the mechanical properties. For example, most nickel-base superalloys lie very close to the sigma-forming boundary, and silicon promotes sigma formation. The use of silicon- containing coatings for this application must therefore be approached with care.

In the subsequent sections, some examples of these different processes will be described. Some of these examples, and others, are discussed in more detail in other papers in this Symposium. In addition to describing the practical problems, the methods of combating each will be briefly discussed.

\section{Oxidation and exfoliation in boiler steam circuits: the problem of solid particle erosion.}

Fossil-fired utility boilers generate superheated steam; for most units in the United States the final steam temperature is $1000^{\circ} \mathrm{F}\left(538^{\circ} \mathrm{C}\right)$. The materials of which the superheater tubes and pipes are made in the US are limited by the American Society of Mechanical Engineers (ASME) Boiler Code; other countries have similar codes. These codes are concerned with the mechanical properties of the materials, and for the superheater conditions relate primarily to the creep properties. The steam temperature, and hence the metal temperature, rises from the saturated steam temperature entering the superheater to the finishing temperature, and the permitted materials consequently also change. The finishing sections of the tubing and the pipes that take the steam to the high pressure turbine may be of the low-alloy ferritic steel Fe-2.5\% Cr-1\%Mo (T22 or P22); the ferritic steel Fe-9\%Cr-1\%Mo (T9 or P9); or an austenitic stainless steel such as Type $304(\mathrm{Fe}-18 \% \mathrm{Cr}-8 \% \mathrm{Ni})$. All of these alloys do not normally lose a significant amount of section as a result of oxidation at the steam temperature.

There are two problems associated with the oxidation. First, the oxide has relatively low thermal conductivity. In the heated part of the system, there is a temperature gradient from the external gas temperature through a gas boundary layer, through any external deposit layer, through the external oxide layer, through the metal, through the internal oxide layer, and finally through a steam boundary layer to the steam temperature. These several temperature drops are related to the heat flux, which is largely a requirement imposed by the power required by the system, and the thermal conductivities and thicknesses of the different layers. From the point of view of the metal lifetime in terms of creep failure, the most important temperature is the metal temperature. If the steam temperature and the heat flux are essentially fixed, the external temperature drops through the gas, the deposit, and the external oxide do not affect the metal temperature. However, the temperature drop through the internal oxide does result in an increase in the metal temperature, and thus a shortening of the creep life of the tubes. This is an important technical problem, and the thickness of the internal oxide is used to calculate the thermal history of the metal and predict the remaining creep life. This is principally a problem with the ferritic steels. However, it will not be further discussed in this paper, because, at least to date, oxidation control procedures are not used in this context. 
The second problem is that the oxide may separate from the metal surface periodically "exfoliate" or "spall". The spalled oxide may, in some circumstances, collect at the bottom of "hairpin" bends in the superheater platens, and restrict the flow of steam. Since the superheater consists of a number of parallel circuits, the steam preferentially flows down the unblocked tubes. The effect of this is to raise the temperature of the partially blocked tubes, which may then fail in creep, since the pressure is the same in all the tubes. A more common problem is that the spalled oxide is entrained in the flowing steam; and this is certainly the problem with scale that spalls in the piping. The entrained oxide particles result in severe erosion damage of the main steam valve and the steam turbine blades and vanes. After exiting the high pressure steam turbine, the steam is returned to the boiler and reheated to a temperature which is typically the same as that of the main steam, although at a lower pressure. This steam is then expanded through the intermediate pressure turbine. The same problems with scale exfoliation and erosion occur in the reheat circuit as in the main superheat circuit. This problem is called solid particle erosion (SPE) and was first identified as a major problem for the utilities in the early 1980's, although reports on the phenomenon had been published earlier [2]. A Workshop to review the problem was arranged by EPRI and ASME in 1980 [3], and a later Workshop was held in 1989 [4]. An ASME/EPRI survey in 1980 estimated the annual cost of SPE to US utilities as $\$ 100$ million, and a later study suggested that the cost had risen to $\$ 150$ million per year [5]. These costs have promoted considerable study of the problem, using two principal approaches:

1) Reducing the oxidation rate or the oxide spallation rate of the boiler materials.

2) Increasing the tolerance of the steam turbine for solid oxide particles.

Reducing the oxidation rate has the benefit of reducing the metal temperature rise. For example, for a typical unit, the oxide thickness on the steamside of the finishing superheater after approximately $3.5 \mathrm{y}$ was $250 \mu \mathrm{m}$, and the consequent increase in tubewall temperature for constant steam conditions was $60^{\circ} \mathrm{C}$; the use of a chromating treatment resulted in a scale thickness in the same time period of only $45 \mu \mathrm{m}$ and a temperature rise of $12^{\circ} \mathrm{C}$. Two principal approaches have been developed for reducing the oxidation rate: the first is chromating, in which a chromic acid-containing solution is introduced into the superheater (and reheater) circuits and heated: a chromium-rich oxide deposit forms on the metal surface which is incorporated into the subsequent scale [6]. The effect of this is to reduce the growth rate by a factor of about three, but otherwise the scale looks much the same. Typically, a two-layer magnetite scale forms, with the chromium rich material at the interface between the two layers. The advantage of the chromating approach is that, in principle, it can be applied to an existing boiler. The second approach is chromising, in which a CVD technique is used to produce a chromium-rich diffusion layer on the inside of a tube. This is very effective, in that the magnetite scale is replaced by a slow-growing chromium-rich $\mathrm{M}_{2} \mathrm{O}_{3}$ scale. However, it is a technique for new boilers or for retubing older units.

The amount of oxide that spalls can be reduced by periodically chemically cleaning the boiler: this removes the scale. It appears that the scale starts to spall only after it has attained some critical thickness: if the cleaning is done before the scale reaches that thickness, spalling is eliminated or greatly reduced.

However, at the moment the most commonly used approach is to coat the turbine components at risk with an erosion-resistant layer. General Electric developed an erosion-resistant plasma spray coating that reduced wastage by as much as a factor of ten [7]. Boride diffusion coatings have also been considered. The experience with these different approaches is described in reference [4]; a recent report on the performance of advanced boride diffusion coatings has been published [8]. 


\section{Spalling of alumina and chromia scales: a life-limiting process for coatings.}

Hot section gas turbine components have severe materials requirements [9]. First, they must have adequate creep strength, or (more properly) adequate creep rupture life. Second, they must have enough fracture toughness to resist being broken by the impact of entrained relatively massive objects in the gas stream ("foreign object damage; FOD"). Third, they must be resistant to the thermomechanical fatigue process described briefly above. Fourth, they must be stable at operating conditions, so that, for example, they do not embrittle with time. Fifth, they must be fabricable into the extremely complex shapes required: typically a gas turbine blade, for example, is cooled so that the metal temperature is around $850-900^{\circ} \mathrm{C}$ while the hot gas may be $1350{ }^{\circ} \mathrm{C}$. The cooling is achieved with air from the high pressure compressor, which itself may be $400{ }^{\circ} \mathrm{C}$ : to do this, very intricate shapes must be formed inside the hollow blade, and in places the metal is quite thin. For the most advanced systems there is a further metallurgical requirement: they must be capable of undergoing directional solidification to produce a columnar grain structure, or, in the extreme, form a single crystal airfoil. Sixth, they must have an adequate oxidation life; and finally they may also be required to be resistant to molten salt-accelerated corrosion, which will be discussed later.

Oxidation resistance at these temperatures requires the formation of a protective oxide. As has often been pointed out, the possible oxides are alumina, $\mathrm{Al}_{2} \mathrm{O}_{3}$, chromia, $\mathrm{Cr}_{2} \mathrm{O}_{3}$, or silica, $\mathrm{SiO}_{2}$; but chromia is unsuitable in high velocity oxidising gases at this temperature, and (at least at the moment) silica is not a possible protective oxide scale because of the effect that silicon would have on the mechanical properties and metallurgical stability of the alloys. Generally, it is very difficult to design an alloy which satisfies all the mechanical and metallurgical requirements and still is capable of forming an alumina scale. Consequently, current practice is either to enrich the surface in aluminium using a CVD (chemical vapour deposition) process (the simplest and oldest method of doing this is pack aluminising); or to apply a distinct coating to the component as an overlay (the most common approach is still physical vapour deposition, PVD; but various modifications of plasma spray processes are becoming more important, particularly if the desired coating contains elements with very low vapour pressures, such as hafnium or tantalum). The problem in either case is that the maximum permissible thickness of the aluminium-rich surface layer is only of the order of $100 \mu \mathrm{m}$, for a variety of reasons. The alumina scale thickness is typically $1-5 \mu \mathrm{m}$, and this represents a larger effective fraction of the surface layer thickness, because it is composed only of aluminium, whereas the surface coating layer is typically $25-50$ at $\%$ Al. Because of the difference in the coefficient of thermal expansion of alumina and the underlying alloy, there is a likelihood that the oxide layer will spall when the engine cools on shutdown. When the engine is restarted, the protective scale must reform; and it is obvious that this process cannot be repeated very often, and this oxide spallation process is usually the life-determining process for the coating; the dissolution of aluminium into the substrate is another possibility, but up to now this has been of secondary importance. Further rises in metal temperatures and the development of spallation-resistant coatings may make this process of more significance in the future. As a result, the spallation of $\mathrm{Al}_{2} \mathrm{O}_{3}$ has received a lot of study. It is well-known that small amounts of certain reactive elements, notably yttrium and hafnium, very greatly improve the spalling resistance: this topic is discussed in considerable detail in other papers at this meeting.

The reason for the beneficial effect is still not fully understood. Early models suggested that the effect of the reactive element was to produce a convoluted interface - "pegging" or that the reactive element acted as a vacancy sink, preventing vacancies introduced in the oxidation process, either as a result of the transfer of atoms from the metal to the oxide, or 
as a result of the activation of vacancy sources within the metal, from condensing as voids at the oxide/metal interface. Later, it was suggested that the segregation of the reactive element to the oxide grain boundaries was important, either blocking grain boundary transport of one or the other oxide- forming species, or modifying the generation of stress in the growing oxide. The most recent proposal is that an impurity such as sulphur in the metal segregates to the intrinsically strong metal/oxide interface, and weakens it, leading to spallation; the role of the active element is to getter the harmful impurity. From a practical point of view, these different models only matter if they help to direct the research to overcoming some practical problem.

One issue in the case of the use of reactive elements is that they often form coarse intermetallic phases in the alloy (this includes a coating) grain boundaries, which can lead to hot shortness in the case of alloys, or to grain boundary cracking in the case of coatings. Furthermore, the coarse intermetallics can actually induce local oxide failure if the amount of the reactive element added is too great: generally, less than $0.5 \mathrm{wt} \%$ should be used. This is not really an issue in the case of coatings for gas turbine components. There is enough understanding of these problems that a satisfactory coating can be produced; while improvements are certainly possible, the directions for improvement are well known. However, there is an increasing interest in developing high-strength alloys with intrinsic oxidation resistance without need for a coating. This is because of the interest in single crystal blades: the use of a polycrystalline coating could possibly destroy the benefits of the absence of grain boundaries in the underlying alloy. The concept of impurity-induced spallation is particularly interesting from this point of view. While sulphur has been identified as the impurity of particular concern, it is well-known that many impurities tend to segregate to or near to the grain boundaries in the metal, and thus may well segregate to the metal surface or to a metal/oxide interface. These may or may not affect the scale adhesion, but it seems likely that some may be as harmful as sulphur is suspected to be. If the harmful species can be identified (and assuming there are not too many of them!) it should be possible to control the problem by using good metal production and fabrication practices, because the development of alloys low in the critical impurities should not be too difficult, and should not otherwise affect the properties of the substrate alloy. Surface modification techniques such as ion-implantation might also be interesting in this context, although the long-term ability of ion-implantation to inhibit spallation is not clear.

The general problem of the spalling of an oxide scale from a metal - the origin of the stresses that lead to failure, the location of the failure - at the interface, or within the oxide or the metal - is not well-understood. The paper by Wood and Stringer [10] in this meeting discusses the current state of knowledge of this topic in more detail.

\section{Molten salt induced corrosion in gas turbines.}

Even if a gas turbine hot component does not suffer from protective scale spallation as a result of thermal cycling, the protective scale may still be destroyed as a result of the deposition of molten salt species on the hot surface during operation [11]. In a gas turbine the molten salts may be oxides such as vanadium oxide $\mathrm{V}_{2} \mathrm{O}_{5}$, or less-commonly lead oxide or phosphorus pentoxide; or sulphates such as sodium sulphate, $\mathrm{Na}_{2} \mathrm{SO}_{4}$. The source of the salt-forming impurities may be the fuel or the intake air: in the case of vanadium it is usually the fuel; in the case of sodium it is more frequently the air. The mode of formation of the salt species is a matter of debate, but again from a practical point of view it only matters if the understanding will help in developing a solution to the problem. 
The accelerated attack in the presence of vanadium pentoxide is almost certainly due to the dissolution of the protective oxide. Vanadium pentoxide melts at $710^{\circ} \mathrm{C}$, and the melting point can be lowered somewhat by other species. Molten $\mathrm{V}_{2} \mathrm{O}_{5}$ appears to dissolve almost any oxide, and it readily wets most oxide surfaces. It has been reported that the attack is more severe in the presence of sodium, but it is not clear that this matters, since the attack of the vanadium is severe by itself. There are three solutions for this problem in the gas turbine: first, eliminate the vanadium from the fuel; second, use an additive which forms a higher-melting point complex with the vanadium ( $\mathrm{MgO}$ in one form or another is the usual choice); or third, use a vanadium oxide-resistant alloy or coating. The only commercial alloy which exhibits some resistance to vanadium attack is $\mathrm{Ni}-50 \% \mathrm{Cr}$, which is very weak at elevated temperatures; under the high-velocity oxidising conditions in a gas turbine the intrinsic oxidation resistance is probably inadequate because of the further oxidation of the protective $\mathrm{Cr}_{2} \mathrm{O}_{3}$ to form the gaseous species $\mathrm{CrO}_{3}$. For some industrial turbines burning cheaper impure fuels this may be a possible approach so long as the turbine inlet temperature is below $850^{\circ} \mathrm{C}$.

The accelerated oxidation produced by sodium sulphate deposition, called hot corrosion, is more difficult to avoid in aircraft gas turbines. In land-based engines the use of good and well-maintained air filtration systems, the avoidance of air intakes pointing towards the sea or other source of air that may be contaminated by impurities - from industrial processes, agricultural fertilisers, and road dust, among others - ameliorates the problem considerably. Good fuel specification, and appropriate precautions in ensuring the cleanliness of the delivery and storage systems, will eliminate fuel-borne impurities, although there will be cost implications. If this is then supplemented by regular cleaning of the airfoils, the problem can largely be contained. However, the total mas flow of air through a large gas turbine is very high. Aerosol salt particles will not generally be removed by filter systems, but they can be separated out by the compressor, and periodically shed as larger particles which deposit on the hot section components, so that for base-loaded advanced gas turbines this may become a more severe problem. Periodic washing of the engine may be able to control the corrosion.

There are two modes of hot corrosion. The first of these is now called Type I hot corrosion. It appears at a temperature of approximately $800^{\circ} \mathrm{C}$, and is essentially absent above $950^{\circ} \mathrm{C}$. It appears to be associated with sodium sulphate, $\mathrm{Na}_{2} \mathrm{SO}_{4}$, and the lower threshold temperature is associated with the melting point of the salt, and the upper threshold with its dew point.

Type II hot corrosion (also called low power hot corrosion) appears at temperatures in the range $700^{\circ} \mathrm{C}$, and is absent above approximately $780^{\circ} \mathrm{C}$. Again, the low temperature limit is related to a melting point, but of a complex sulphate $\mathrm{Na}_{2} \mathrm{SO}_{4} .\left(\mathrm{M}_{x} \mathrm{SO}_{4}\right)_{n}$, where $\mathrm{M}$ is Co, $\mathrm{Fe}$, or $\mathrm{Ni}$ (there are other possibilities, but these have not been demonstrated in practice: by far the majority of cases of low-temperature corrosion in practice involve cobalt). The upper temperature is the dissociation temperature of the complex sulphate, which itself is a function of the $\mathrm{SO}_{3}$ partial pressure, $p_{\mathrm{SO}_{3}}$, because the stability of the transition metal sulphates is relatively low: in low $p_{\mathrm{SO}_{3}}$ they tend to dissociate to form the oxide and $\mathrm{SO}_{3}$, and this would cause the melt to solidify: no corrosion would occur (but see the later discussion of fluidised bed corrosion).

The corrosion morphologies developed in these two forms of hot corrosion are quite different. In Type I, the interface between the alloy and the corrosion product is macroscopically plane, although microscopically rough and convoluted. The corrosion product layer is essentially a mixture of oxides; close to the metal surface the layer may contain particles of unreacted metal, which is base metal (typically Ni or Co) -rich; the product layer is porous, and may contain the sulphate in the pores. There are internal sulphides, which are generally chromium-rich, in the metal; and chromium-rich oxide intrusions are also present in the 
metal, appearing to result from oxidation of the sulphides. In the case of Type II, the surface is macroscopically rough, with relatively large pits, typically having a more or less hemispherical shape; but microscopically smooth: the pits all have very smooth surfaces. The corrosion product within the pits may contain quite large amounts of sulphide. There is essentially no penetration of sulphides into the metal, or depletion of alloy elements from the underlying alloy. Sometimes, with some alloys, a form intermediate between these two can be observed.

It is well-known that chromium is beneficial in combating hot corrosion, of both types; and for adequate hot corrosion resistance an alloy should normally contain more than $15 \% \mathrm{Cr}$. This is true even if the alloy is an alumina-former, with no apparent chromium present outside the protective scale. The reasons for this beneficial effect of chromium is not well-understood. Molybdenum is bad: for nickel-base alloys, amounts of Mo above approximately 3.5wt\% are likely to reduce the hot-corrosion resistance. Sometimes, the molybdenum is partly present as carbides; if these are coarse, they are particularly harmful. It appears that the role of the Mo is to dissolve in the molten salt, displacing it in an acid direction. In the development of Nibase superalloys, Cr was at first used to provide both oxidation resistance and solid-solution strengthening. Later, the remarkable ability of the $\gamma^{\prime}\left(\mathrm{Ni}_{3} \mathrm{Al}\right)$ phase to confer strength was recognised, and the $\mathrm{Cr}$ content was reduced to increase the solubility of $\mathrm{Al}$ and $\mathrm{Ti}$; the solid solution strengthening was replaced by adding Mo for density reasons. However, modern alloys replace some or all of the Mo with $\mathrm{W}, \mathrm{Ta}$, and/or $\mathrm{Nb}$.

Other alloy-element effects on hot corrosion have been suggested, but the evidence is limited.

\section{The use of coatings to protect gas turbine hot components.}

Coatings have been used for a long time to protect gas-turbine hot components, as has been indicated above; this subject is a major topic for this meeting, and several papers summarise the current state of knowledge: the review papers by Streiff and by Goward are particularly relevant. In this paper, a very brief summary will be presented for completeness.

All current high-temperature coatings are designed to form a protective $\mathrm{Al}_{2} \mathrm{O}_{3}$ scale. The earliest form of coating involved the use of a diffusion pack to enhance the aluminium concentration at the alloy surface, eventually developing an outer layer of $\mathrm{NiAl}$, and this is still the most commonly used coating system. A few years ago, it was discovered that the initial deposition (usually by electrolysis) of platinum (or another platinum-group metal) prior to the aluminising greatly improved the coating performance, and these platinum aluminide coatings are also widely used.

In nearly all practical situations in the absence of hot corrosion, the life-limiting factor is the depletion of aluminium as a result of repeated spalling and regrowth of the protective alumina scale. In hot-corrosive situations a simple aluminide may not be adequately protective. As a result, a group of coatings based on the M-Cr-Al-Y system, where $M$ was most commonly cobalt, but now may also be nickel or a combination of the two, were developed by Part and Whitney Aircraft. These coatings are applied by electron beam physical vapour deposition (EB-PVD). In their original form, they were developed primarily for oxidation resistance, and the aluminium was high and the chromium low. However, they were soon shown to have very poor low-temperature Type II hot corrosion resistance, principally because they were cobalt based. Alternatives with higher chromium and lower aluminium (although still alumina formers), and based on $\mathrm{Ni}$ or $\mathrm{Ni}+\mathrm{Co}$ were developed for these more arduous duties. However, in some practical applications, for example in carrier-based military aircraft, the coating is required to provide resistance to both high-temperature oxidation, and to low- 
temperature hot corrosion. This requires some rather difficult compromises, and the coating still has to satisfy some mechanical requirements, in particular that it does not crack in service, or at least that the cracks do not propagate into the substrate.

A problem with some coatings is that some elements from the substrate alloy can diffuse out rapidly through them, and under some circumstances induce local corrosion which may then spread and destroy the coating.

Most turbine manufacturers are unwilling to rely entirely on a coating for protection, and if an engine is to be used in a situation where hot corrosion is a possibility, it is normal to specify base alloys with some reasonable resistance, and then use a coating as well.

A special coating problem is the inside of the cooling passages. This can be expected to increase in importance, and obviously neither PVD nor plasma spray processes can be used. The only technique capable of producing an acceptable coating would appear to be vapourphase chemical vapour deposition.

Coupled with the good operational practices described above, hot corrosion has not been a major problem in most land-based applications in the recent past. There are special situations where it continues to be an issue: turbines burning very low-grade fuels, or industrial units in very polluted environments, or where good maintenance practices cannot be counted on; and marine turbines, particularly in surface-effect vessels; the newer potential problems associated with large advanced turbines have been mentioned above.

Aircraft turbines operating in marine environments or some special routes over salt deserts may still be subject to hot corrosion, because it is generally not possible to filter the intake air.

\section{Molten salt induced corrosion of superheaters in boilers.}

Fireside corrosion of superheaters in both oil-fired and pulverised-coal (PC)-fired boilers has been known a long time.

Vanadium-induced attack is experienced in oil-fired boilers. Here, the role of sodium is more important than in the case of the gas turbine since the metal temperatures seldom exceed $650^{\circ} \mathrm{C}$; the primary effect is to produce a lower-melting point salt, although a number of authors have attributed a special role to complex sodium vanadium oxides, or to changes in the melt acidity. These postulates are almost certainly unnecessary in the practical situation. Again, an MgO additive is effective, although it can result in increased deposition. The use of a high-chromium cladding is also possible, and coextruded tubes with a $\mathrm{Ni}-50 \% \mathrm{Cr}$ outer layer have been fabricated commercially for severely corrosive boiler applications. Another approach is to decrease the excess air to the lowest level consistent with good combustion. The reason for this is that the vanadium initially oxidises to $\mathrm{V}_{2} \mathrm{O}_{4}$; this is a relatively high meltingpoint oxide. In an oxidising environment this subsequently oxidises to the pentoxide, and apparently this can be inhibited by lowering the excess air.

In coal-fired boilers superheater corrosion is mainly a problem on the leading finishing superheater tubes; the finishing reheater tubes may also be subject to attack, depending on the design of the boiler. The problem is well-understood [12]. The metal temperature is typically $600^{\circ} \mathrm{C}$ to perhaps as high as $650^{\circ} \mathrm{C}$. The local gas temperature may be as high as $1400{ }^{\circ} \mathrm{C}$, but $1250^{\circ} \mathrm{C}$ would be more typical. A deposit forms on the leading edge of the leading tubes, composed of coal ash. The deposit may be as thick as $100 \mathrm{~mm}$, although 25 $\mathrm{mm}$ would be more typical. Close to the metal surface there is a white layer, which turns out to be largely alkali sulphate; the sodium/potassium balance depends on the coal. In this location, it is unlikely that the alkali sulphates would be molten. Severe corrosion, in the form of large pits, takes place: the location of the maximum attack is usually close to the edge of the 
deposit-covered region. The molten species was shown to be an alkali-iron trisulfate (AIT), $(\mathrm{Na}, \mathrm{K})_{3} \mathrm{Fe}\left(\mathrm{SO}_{4}\right)_{3}$, which has a minimum melting point of $554^{\circ} \mathrm{C}$ at a $\mathrm{Na}: \mathrm{K}$ ratio of $2: 3$. This compound is only stable at these temperatures if $p_{\mathrm{SO}_{3}}$ exceeds $25 \mathrm{~Pa}\left(2.5 \times 10^{-4} \mathrm{~atm}\right.$, or 250 ppm). This is higher that the usual $p_{\mathrm{SO}_{3}}$ in a PC boiler, but this is because of the sluggishness of the $2 \mathrm{SO}_{2}+\mathrm{O}_{2}=2 \mathrm{SO}_{3}$ reaction; in the neighbourhood of an iron or iron oxide surface the local $p_{\mathrm{SO}_{3}}$ will attain a value in excess of $25 \mathrm{~Pa}$ because these surfaces are catalytic for this reaction.

The pitting attack is closely similar to that observed in Type 2 hot corrosion, which is scarcely surprising, since the mechanisms are basically the same. The form of the attack, pitting with little or no internal attack or depletion within the alloy, led some investigators, notably Rehn [13], to suggest that the process may involve a local cell electrochemical attack, analogous to pitting corrosion in aqueous media.

Alloys in laboratory testing show attack increasing with rising temperature to a maximum, followed by a rapid decline. This has been called the "Bell-Shaped. Curve", and generally the temperature corresponding to the maximum attack is more or less the same for all alloys, although the degree of attack is very different. As with gas-turbine hot corrosion, high-chromium alloys are generally more resistant, and high levels of molybdenum are to be avoided.

There has been some success over the years in avoiding trouble by careful selection of coal; and additives have been tried, with only limited success. In units suffering severe attack, "bandages", usually of Sichromal have been wrapped around the sections of the leading tubes with some success: in effect, the bandage catches the ash and the alkali, and since the thermal contact with the tube is limited, the bandage runs slightly hotter than the tube surface. Another approach is to use coextruded tubes, with the inner layer being the normal alloy, and the outer being a corrosion-resistant alloy. Experience has been gained with Type 310, Incoloy 800 , and $\mathrm{Ni}-50 \% \mathrm{Cr}$ as the outer layer: Type 310 appears to be adequate, reducing the overall rate of attack by a factor of approximately three.

\section{Waterwall corrosion in coal-fired utility boilers.}

The waterwalls of boilers also may undergo rapid wastage. This typically occurs a little above the burner level, and underneath a deposit which contains iron sulphide and unburned carbon. The metal temperature in this region is usually less than $450^{\circ} \mathrm{C}$. The early investigators suspected that this too was alkali sulphate induced, but the only species with a melting point anywhere near this is the pyrosulfate, $(\mathrm{Na}, \mathrm{K})_{2} \mathrm{~S}_{2} \mathrm{O}_{7}$. This requires an even higher $p_{\mathrm{SO}_{3}}$ to prevent it dissociating before melting, and since the local $p_{\mathrm{O}_{2}}$ must be low, because of the presence of free carbon, it follows that the local $p_{\mathrm{SO}_{3}}$ must also be low. In fact, this is an example of mixed oxidant attack, which will be discussed later; it is possible that chlorine may be a contributor to the attack, but this is a matter of debate [14]. The methods of controlling this are: first, to correct the burners to ensure a proper combustion zone within the furnace; second, to use an "air blanket" injected near the bottom of the wall and flowing upwards to attempt to provide an oxidising blanket; and third, the use of a coating or cladding. For some time, a three- layer flame-sprayed coating system was promoted for this purpose: the innermost layer was an exothermic layer to provide a good metallurgical bond with the steel substrate; the second layer was aluminium; and the final layer was a sealing layer to close the porosity in the flame-sprayed aluminium coating, which is otherwise a significant disadvantage. However, this concept appears to have fallen into disuse. At the moment, flame-sprayed or plasma sprayed alumina coatings are used only as palliatives in locations suffering damage 
until some more permanent solution is installed. Clad tubes have also been used to combat this problem. However, the best approach is to attempt to cure the root cause.

\section{Mixed oxidant corrosion [15].}

Mixed oxidant corrosion is the situation where the most stable corrosion product is a protective oxide, and for simplicity in this discussion it will be assumed that this is chromium oxide. If a second oxidant, for example sulphur, is present, it may migrate inwards through the oxide and react within the alloy with chromium to form a dispersion of chromium sulphide in a chromium-depleted alloy matrix. It used to be thought that this by itself would prevent the reformation of a new chromia scale in the event that the initial protective layer was disrupted, but it has been shown frequently that, so long as the dispersed phase is less stable than the oxide, an alloy containing a dispersed phase of a compound of the stable oxide former is capable of forming an external protective scale. As has been said, it is the availability of the oxide-forming element in the alloy, not its activity, that matters. One important factor is the form of the distribution of the second phase. A fine distribution can form a protective external oxide; a coarse distribution frequently can not. A second, and perhaps more important, factor is this: if the oxygen and metal diffusivities (or rates of other transport processes) are such that the second phase oxidises within the metal, to form an internal oxide dispersion, it becomes very difficult (virtually impossible) to form an external protective oxide. In many cases, a reaction process is established which generates a self-propagating internal oxide formation. This has been termed a "critical microstructure"(Ref. [1]) and the steps towards the breakdown of the ability of the alloy to form and maintain a protective external oxide are related to the development of this critical microstructure. In the case of sulphur-induced attack, the steps involve a gradual coarsening of the internal sulphides, their development into fingers extending inwards along grain boundaries and similar features, and their oxidation in situ to form chromium oxide penetrations into the metal, with a sulphide "leader" at the tip. The oxidation of the sulphide automatically generates a porous oxide finger, because the volume of oxide per metal ion is less than that of the sulphide, and in the internal environment where the reaction takes place, the metal cannot relax back to accommodate the volume change. This mechanism was developed to explain the eventual breakaway corrosion of certain alloys in fluidised bed environments. However, more careful study revealed that, while correct in general form, it was incomplete [16]. It is impossible to generate the reaction morphology in $\mathrm{H}_{2}-\mathrm{H}_{2} \mathrm{O}-[\mathrm{S}]$ environments, but possible in $\mathrm{CO}-\mathrm{CO}_{2}-[\mathrm{S}]$ environments having the same oxygen activity. In addition, careful examination of corroded samples from practice revealed the presence of grain boundary carbide films in advance of the sulphides. Apparently, the carburisation plays a key role in the development of the critical microstructure.

One of the most important questions is how the second oxidant gets through the protective scale in the first place. A major contribution to this came from the work of Perkins (reported at this Conference) who reported that if the protective chromia scale is first grown in an atmosphere free of sulphur, the scale subsequently does not appear to allow the transfer of sulphur across it, even at relatively high sulphur partial pressures. However, if the scale is grown in an atmosphere containing even a very small trace of sulphur (for example, equivalent to an activity of $10-30 \mathrm{bar}$ at $1000^{\circ} \mathrm{C}$ ) the scale is subsequently rapidly penetrated when the sulphur pressure is raised to values above the equilibrium partial pressure for chromium sulphide formation. This can only be explained by postulating a strong chemisorption of a sulphur species on the surface of the growing oxide, which is built into the oxide - probably at the grain boundaries - as the oxide grows. However, Perkins was able to detect no difference 
in the scales with the techniques then available. This is a very important result which should be repeated.

Phase stability diagrams were originally developed for the interpretation of metallurgical extraction processes, and their use in the understanding of mixed oxidant (and, in a modified form, molten salt corrosion) processes dates from the late 1960's, involving Gulbransen and Jansson, Goward and Pettit, DeGrescente and Bornstein, and Stringer. They do not have any real predictive capability, but they are very useful in interpreting the sequence of phases which develop in corrosion reactions, and, especially, identifying those results which are unexpected, and thus give important insights into the mechanisms of the reactions. The power of this tool was increased with the introduction of the concept of the "reaction path" by Whittle and Stringer [17], and developed in some detail by Stringer [18].

\section{In-bed corrosion in fluidised-bed combustors [19].}

If air is blown upwards through a bed of particles they eventually reach a stage where they levitate, and move relatively freely with respect to one another, while being constrained by the necessity for contact. This is fairly similar to the relationships between the molecules in a liquid, and in fact the bed of particles behaves in many ways like a liquid: it is said to be fluidised. The gas/solid contact is excellent, and so a fluidised bed is very good for conducting gas/solid reactions. Furthermore, the heat transfer characteristics are remarkable. For these reasons, it forms an ideal medium for combusting coal: complete combustion can be achieved at low temperatures, and the enhanced thermal transfer characteristics means that heat can be extracted from the bed without the large increase in heat exchanger surface that the low combustion temperature would otherwise imply. Furthermore, by adding calcium carbonate to the bed, the sulphur in the coal can be captured in the bed as calcium sulphate. In a bed operating at atmospheric pressure, this process involves initially the calcination of the carbonate to form calcium oxide, and then the sulphation of the oxide. If the air blown through the bed is in excess of that required to fluidise it, the excess is present in volumes which have a low particle density. In many (but, importantly, not all) respects, these resemble bubbles, and the bed is called a bubbling fluidised bed. It was not initially expected that corrosion would be a problem, but Stringer and Ehrlich [20] pointed out that measurements of the in-bed oxygen potential (partial pressure) made by Cooke $e$ t al. [21] using a stabilised zirconia probe implied that corrosion was a possibility, and subsequent experiments in beds at the Coal Research Establishment showed that this was indeed the case. The in-bed oxygen measurements have been repeated many times since, and indicate that there is a fluctuation, with a period typically in the order $0.5-2.0 \mathrm{~Hz}$, of from close to atmospheric pressure to $10^{-16} \mathrm{~atm}$. Stringer and Ehrlich pointed out that in the presence of calcium sulphate and calcium oxide at $900^{\circ} \mathrm{C}$, this lower oxygen pressure was capable of generating a sulphur activity of the order of 10-6 atm, and the combination of the low oxygen activity and the high sulphur activity, while still lying in the "oxide- stable" range, could nevertheless suffer sulphidation/oxidation corrosion of the type described above. This was observed for certain "sensitive" alloys, the most important example of which is Incoloy 800 , at metal temperatures in excess of $650^{\circ} \mathrm{C}$. Considerable research into this problem resulted in a set of guidelines, which included selection of material, limits on metal surface temperature, and monitoring and control of the oxygen potential distribution within the bed. If these requirements are satisfied (and they do not place important limits on the operation of boilers), the problem is easily controlled. From time to time, there are attempts to develop the "air-heater" fluidised bed combustor, where the aim is to produce air heated to $950^{\circ} \mathrm{C}$ or so to expand through a 
gas turbine. In this case, the heat exchanger presents considerable potential problems.

As mentioned above, attempts to reproduce the attack in the laboratory were successful, when $\mathrm{CO} / \mathrm{CO}_{2}$ mixtures with oxygen potentials of the order of $10^{-16} \mathrm{~atm}$ were passed over $\mathrm{CaO} / \mathrm{CaSO}_{4}$ mixtures at $950^{\circ} \mathrm{C}$ or so, and then over a specimen. This showed that the role of the solid salt in this case was primarily to generate sulphur activities: this illustrates the point made earlier that a solid salt can, under some circumstances, induce accelerated attack.

However, again as mentioned above, the corrosion was not induced when $\mathrm{H}_{2} / \mathrm{H}_{2} \mathrm{O}$ mixtures with the same oxygen activity were used, demonstrating the role of carbon in the reaction.

\section{Mixed oxidant corrosion in gas turbines.}

In the earlier section, the involvement of molten salts in gas turbine hot corrosion was summarised. Various field observations have suggested that certainly Type 1 hot corrosion involves an incubation period when the rate is not accelerated, even in the presence of molten salt. There is then an acceleration - "breakaway" - followed by a rapid propagation stage in which the reaction morphology described earlier develops. A qualitative hot stage microscopy experiment conducted by Goebel and Pettit [22] consisted of preoxidising a specimen, then putting sodium sulphate crystals on the surface. These melted, and for a time the molten salt is visible on the outer surface: nothing happens, and there is no colour change in the salt, which might perhaps be expected if the salt was dissolving a transition metal oxide. Then the salt abruptly disappears, and the oxide layer "waves" - indicating that it had lost contact with the metal surface. Otherwise, it looks much the same; and there is no evidence of massive break-up of the scale. Later examination showed that the salt was now beneath the detached scale layer. This is a reason where the oxygen activity would be expected to be low, and by analogy with the same alloys in the calcium sulphate case, sulphidation/oxidation corrosion would be a possibility. In fact, Spengler and Viswanathan [23], and later Stringer and El Dahshan [24], were able to duplicate essentially all the Type 1 hot corrosion morphological features in nickel-base superalloys by an initial sulphidation followed by oxidation, in the absence of any molten salt phase. This does not imply that salt- fluxing is unimportant, but it serves to illustrate that other factors may be important in the practical system.

\section{Mixed oxidant corrosion in coal gasification systems.}

This topic is the subject of papers by Bakker and by Perkins in this Conference, and will be only briefly discussed here for reasons of completeness. In a gasification system, the sulphur partial pressure depends on the sulphur content of the coal, but is actually not very much different from that found in a fluidised bed combustor reducing zone (which is not altogether surprising). The oxygen partial pressure is typically somewhat lower, and the gas composition generally lies rather closer to the oxide/sulphide stability boundary in the phase stability diagram. However, they still lie in a region where $\mathrm{Cr}_{2} \mathrm{O}_{3}$ is the stable oxide, although they also lie generally in the sulphide -stable region with respect to iron and nickel. Perkins and Vonk [25], and also Natesan [26], showed that, in the laboratory, the boundary between conditions which produce a continuous external protective chromia scale and those which result in extensive sulphide formation and rapid non- protective attack lies parallel to, but displaced from, the thermodynamic boundary between $\mathrm{Cr}_{2} \mathrm{O}_{3}$ and $\mathrm{CrS}$. This is now called the "kinetic boundary", but a mechanistic argument for its existence and location is lacking. A very important point is that, in practice, the gas mixture produced, at least in entrained 
gasifiers, appears not to be at equilibrium. Furthermore, the metal surfaces are much cooler than the gas temperature, and it is difficult to know what values should be taken for sulphur, carbon, and oxygen activities in the vicinity of the reacting surface. Perkins and Bakker [27] have also shown that corrosion at low temperatures during down time, probably induced by hydrolysis of surface sulphides, has a profound effect on the subsequent high temperature attack.

The process here is undoubtedly not that described in the last section. While processes like this may be involved in the destruction of a preformed protective oxide scale, there is little doubt that in the gasifier case a protective scale is never established: the problem is probably competition between sulphide and oxide phases growing in a non-steady-state fashion from the start of the reaction, the recession of the metal surface beneath the more rapidly-growing sulphides effectively destroying the ability of the protective oxide to spread over the surface to provide a "healing" layer.

Research has concentrated mainly on determining the maximum temperature to which materials can be exposed to the environment; the effect of changing the gasification process on the aggressiveness of the environment; the effect of minor impurities such as chlorine; the effect of the actual cycle, as for example in down-time effects; and the possible beneficial effects of protective coatings. The results will again be presented in more detail by Bakker and by Perkins. In summary: plain carbon and low alloy steels can probably not have metals surface temperatures in excess of $400^{\circ} \mathrm{C}$; austenitic materials may provide a little more resistance, but a little over $500{ }^{\circ} \mathrm{C}$ is probably a maximum. The low-water entrained processes such as the Shell entrained gasification process produce gases which are much more aggressive than the hydrogasification processes such as the Texaco entrained gasification process. The higher water content probably results in a higher oxygen potential (whatever that means in this highly non- equilibrium problem) but that alone seems inadequate to explain the difference in corrosion behaviour: Bakker believes that the water molecule may be playing a significant role of itself. The issue of chlorine will be discussed later, but it does seem to play a negative role; this is difficult to reproduce in atmospheric pressure laboratory tests, but in 4 MPa gasifiers, there does appear to be an effect. In the case of coatings, an aluminised coating was tried at the Coolwater Integrated Gasification Combined Cycle plant, but proved to be ineffective: after a comparatively short period the coating was absent over much of the surface. Chlorine in the coal is particularly severe on these coatings. However, a vanadium- containing aluminide has proved to be effective against down-time corrosion effects. It is probable that high-chromium claddings may be effective, but even so, high metal temperatures will probably be unattainable in gasification environments.

\section{The effect of chlorine in the fuel on corrosion.}

Chlorine has been a persistent problem - or suspected problem - in a number of hightemperature corrosion. In the UK, coals with relatively high chlorine contents - above 0.3 $\mathrm{wt} \%$ - are mined, and are used in utility boilers. There have been persistent fireside corrosion problems in some of these units, and the chlorine has been suspected as playing a role. It was at first believed that the chlorine was present in the coal as sodium chloride, but this is now known to be not, in general, the case. However, the chlorine content of the coal was shown to correlate with the deposition of alkali metals on superheater surfaces, and the hydrogen chloride in the combustion gas does appear to act as release agent for the alkalis in the clay minerals; the mechanism of this is not known. Chlorine is not, however, detected in the deposit on the superheater, and is not now believed to play any direct role. 
The situation for the waterwall corrosion is much less clear. While again chlorine is seldom detected in the deposit, there is still some belief that it does play a role. This opinion is based on studies of corrosion in incinerators, where typically the fuel may be high in chlorine (derived from chlorine-containing plastics, such as PVC) and low in sulphur; combustion efficiency is often poor, and local low oxygen activities are common. Rapid metal wastage is experienced, and Krause and co-workers showed many years ago that iron chloride layers could be detected between the oxide scale and the metal [28]. However, it was also shown that this attack was suppressed by sulphur; and since the deposit on coal-fired boiler waterwalls typically contains a considerable amount of sulphur as iron sulphide, it would be expected that any chloride effect would be absent. However, as mentioned above, the investigations of Bakker and Perkins have shown that $\mathrm{HCl}$ in gasifier environments does appear to be capable of producing enhanced attack, although this result does require further definition, and no mechanistic explanation is yet available: the gasification corrosion product is rich in sulphur.

These issues have been discussed in detail in two recent Conference Proceedings (See Refs [14] and [28]).

An earlier controversy was concerned with the effect of chlorine as sodium chloride on the hot corrosion gas turbines. It has been known for a long time that a sodium chloride/sodium sulphate melt is much more aggressive than sodium sulphate itself, and the International Nickel Company used a test for some years which involved half immersing the alloy specimen in a crucible containing a melt of sodium sulphate and sodium chloride. The fact that corrosion was particularly severe in gas turbines that operated in a marine environment encouraged investigators from the British Admiralty to believe that sodium chloride played a significant role. However, U.S. investigators pointed out that sodium chloride is seldom if ever detected in deposits from gas turbines, and that the half-crucible test did not compare well with practical experience in the ranking of alloys. This topic was actively debated in a series of meetings on Gas Turbines in the Marine Environment which extended over the period 1972 - 1979; by the end of these the half-immersion test had been discredited, and the use of sodium chloride in test salts had essentially ceased. The one effect that remained was that demonstrated by Hancock [29], that a trace of sodium chloride vapour was capable of producing an almost immediate and energetic loss of adhesion between a protective scale and the substrate: sodium chloride may thus play role in initiating the attack. However, in general the aggressive species is certainly a sulphate; and research in the last decade has been concerned with this aspect.

Nevertheless, it is important to remember that turbines in industry are exposed to many very specific environments. Cases exist where the hot corrosion turned out to be due to phosphate-rich fertilisers used in nearby farms; lead and sodium-rich salts from glass production, salt used for removing ice from nearby-roads, lead from gasoline in tankers used for fuel transportation, and so forth. It is certainly not impossible that sodium chloride may play a significant role in the corrosion of some gas turbines; but there is now little doubt that it is not a major contributor in the majority of hot corrosion problems.

\section{The interaction of high-temperature corrosion and mechanical effects.}

Finally, the problem of the effect of high-temperature corrosion processes on the mechanical properties of the substrate should be discussed. Effects related to this have been known for a long time. For example, carburisation can severely embrittle materials; the dissolution of oxygen in titanium alloys produces a surface- embrittled layer which may generate a crack which is then in excess of the critical crack length for the substrate; nitrogen dissolution in 
chromium-rich alloys produces chromium nitride needles in the alloy which embrittle the surface. In addition, the depletion of alloys from the surface of the metal, either as the result of the formation of the external scale, or the formation of internal corrosion products, can weaken the surface, and promote failure.

An important issue in practice is thermomechanical fatigue of gas turbine blades and vanes. This is one of the two leading causes of failure of hot components in gas turbines. The vanes and blades are subject to a complex cycle on start-up and shut-down, in which the temperature of the component undergoes considerable changes, which are not only time dependent, but vary with position over the component. In addition, there is a complex stress cycle, partly imposed by the temperature differences, and partly by the duty cycle. The thermal and mechanical cycles are not in phase. In practice, detailed finite element thermomechanical analysis coupled with experimental determinations on actual components, identifies the location where failure is most likely to be initiated, and the stress and temperature cycle for that element can then be imposed on a specimen in the laboratory to generate data for life prediction. The growth of oxide on the inner surfaces of the crack can have a major influence on the crack growth, and hence on the component lifetime: crack initiation is not regarded as the end of useful life.

Oxidation of the inner surfaces of a crack will affect any fatigue limited failure, since the oxide inhibits the crack closing part of the cycle, leading to high stresses at the crack tip.

The stresses induced by oxide growth have been suggested to be a component in low stress, high temperature creep of components, and strains of long tubes attributed to oxide growth stresses were identified in British Advanced Gas-Cooled Reactors (AGR). However, the effect of this process on component lifetime does not appear to have been determined.

Of course, the effect discussed early in this paper, in which the growth of oxide on the inside of a tube resulted in a metal temperature rise leading to accelerated creep rupture failure is properly an interaction between oxidation and mechanical effects, although not of the sort that is generally discussed.

The issue of the interaction between oxidation and high-temperature mechanical wastage processes such as erosion or abrasion has been a topic of theoretical interest for many years. Recently, it has been suggested that these interactions may be important in the technically significant problem of the wastage of tubes in fluidised bed combustors.

The interaction of high temperature oxidation and corrosion on mechanically-limited component lifetimes should be studied in more detail. The first step in any such research should be to identify life-limiting processes which might be expected to be modified by corrosion, rather than looking at possible interactions in general: some of the work done on the effect of corrosion on stress-rupture lifetime of superalloys, for example, seems to have little practical relevance.

\section{Summary.}

While high temperature oxidation and corrosion resistance is seldom a primary criterion for materials selection, these processes have a significant effect on component life in a number of practical situations, including waterwall and superheater tubes in coal-fired utility boilers, in-bed tubes in fluidised-bed combustors, heat exchange surfaces in waste incinerators, hotsection components in gas turbines, heat exchange surfaces in coal gasification systems, heat exchange surfaces in reformers, and various specialised chemical equipment.

Essentially all the practical problems can be grouped into four main classifications: the loss of a protective oxide as a result of exfoliation; the destruction of a protective oxide as a 
result of the presence of a second oxidant; accelerated corrosion in the presence of a molten salt; and interactions between high temperature oxidation and corrosion and mechanical degradation processes.

There are opportunities for research to address these problems, but it is important that research should be at least aware of the nature of the practical problem that is being addressed, and should ensure that the reaction regime in the research is the same as that in practice.

\section{References}

[1] CHOI S.-H., STRINGER J., The Breakaway Corrosion of Fe-Cr Alloys in Atmospheres Containing Sulphur and Oxygen, High Temperature Corrosion of Materials and Engines for Energy systems and Turboengines, R. Streiff, J. Stringer, R. C. Krutenat and M. Caillet Eds. (Elsevier Sequoia, Lausanne, Switzerland, 1987) also Mat. Sci. Eng. 87 (1987) 237-242.

[2] CURRen R. M., A Progress Report on Study of Steam Turbine Erosion By Solid Particles, American Society of Mechanical Engineers Paper 65-WA/PWR-6 (1965).

[3] J. Stringer and J.T. Reese Eds., Solid Particle Erosion of Utility Steam Turbines - 1980 EPRI/ASME Workshop, EPRI CS-3178 (Electric Power Research Institute, Palo Alto, California USA, 1983).

[4] S.R. Murphy Ed., Solid Particle Erosion of Steam Turbine Components: 1989 Workshop, EPRI GS-6535 (Electric Power Research Institute, Palo Alto, California USA, 1989).

[5] Bellanca C., SPE Experience at the J. M. Stuart Station, Report to ASME/EPRI Task Group on Solid Particle Erosion of Steam Turbines, January 1985, quoted by T. McCloskey and C. Bellanca in reference [3] (page 1-1).

[6] REHN I.M., Corrosion Problems in Coal-Fired Boiler Superheater and Reheater Tubes: Steam-Side Oxidation and Exfoliation, EPRI CS- 1811 (Electric Power Research Institute, Palo Alto, California USA, 1981).

[7] WLODEK S.T., Development of Erosion Resistant Coatings, EPRI CS-5415 (Electric Power Research Institute, Palo Alto, California USA, 1987).

[8] Christman T.K., MARTIN C.J., WRight I.G. and Shalvoy R.S., Evaluation of Boride Diffusion Coatings to Alleviate Erosion of Steam Turbine Components, EPRI TR100208 (Electric Power Research Institute, Palo Alto, California USA, 1991).

[9] STRINGER J. and VisWANATHAN R., Life Assessment Techniques and Coatings Evaluations for Combustion Turbine Blades, Life Assessment \& Repair Technology for Combustion Hot Section Components Conference Proceedings, R. Viswanathan and J.M. Allen Eds. (ASM International, Materials Park, Ohio, 1990) pp. 1-18.

[10] WOOD G.C. and STRINGER J., this meeting.

[11] STRINGER J., Mat. Sci. Technol. 3 (1987) 482-493.

[12] STRINGER J., High-Temperature Corrosion in Fossil Energy Systems, in HighTemperature Corrosion in Energy Systems, M.F. Rothman Ed. (The Metallurgical Society of AIME, Warrendale, Penn., 1985) pp. 3-28.

[13] ReHN I. M., Corrosion Problems in Coal-Fired Boiler Superheater and Reheater Tubes: Fireside Corrosion, EPRI CS-1653 (Electric Power Research Institute, Palo Alto, California, 1983). 
[14] J. Stringer and Banerjee Eds., Chlorine in Coal (Elsevier, Amsterdam, The Netherlands, 1991).

[15] STRINGer J., Mixed Oxidant Corrosion in Coal Combustion and Conversion Systems: Manifestations and Mechanisms, High Temperature Oxidation and Sulphidation Processes, J.D. Embury Ed. (Pergamon Press, Toronto, 1990) pp. 257-275.

[16] LIN J.-S., STEVENSON D.A. and STRINGER J., The Role of Carburisation in the In-Bed Corrosion of Alloys in FBC, Proc. 1987 Intl. Conf. on Fluidized Bed Combustion, J.P. Mustonen Ed. (American Society of Mechanical Engineers, New York, N.Y., 1987) 656-662.

[17] Whittle D.P. and Stringer J., Rev. Int. Hte. Temp. Refract. 14 (1976) 6-20.

[18] STRINGER J., Corrosion and Erosion in Complex High-Temperature Environments, The Behaviour of High Temperature Alloys in Aggressive Environments, I. Kirman, J. B. Marriott, H. M. Merz, P. R. Sahm and D. P. Whittle Eds. (The Metals Society, London, 1980) pp. 739-758.

[19] Stringer J. and Minchener A.J., High-Temperature Corrosion in Fluidized Bed Combustion Systems, in High-Temperature Corrosion in Energy Systems, M.F. Rothman Ed. (The Metallurgical Society of AIME, Warrendale, Penn., 1985) pp. 103-128.

[20] STRINGER J. and EHRLiCH S., High Temperature Corrosion in Fluidized Bed Combustors, ASME Paper No. 76-WA/GD-4 (1976) pp. 11.

[21] CoOke M.J., CuTLER A.J.B. and RAASK E., J. Inst. Fuel 57 (1972) 153.

[22] Goebel J.A. and PeTtit F.S., Metall. Trans. 1 (1970) 1943, 3421.

[23] SPengler C. and VisWanathan R., Metall. Trans. 3 (1972) 161.

[24] STRInger J. and El Dahshan M.E., Proc. 1974 Conf. on Gas Turbine Materials in the Marine Environment, J.W. Fairbanks and I. Machlin Eds., Metals and Ceramics Information Center Report MCIC-75-27 (Battelle Columbus Laboratories, Columbus, Ohio, 1974) 161.

[25] Perkins R.A. and Vonk S.J., Materials Problems in Fluidized-Bed Combustion Systems. IV - Corrosion Chemistry in Low Oxygen Activity Atmospheres, EPRI Report FP-1280 (Electric Power Research Institute, Palo Alto, California, 1981).

[26] NATESAN K., Alloy Performance in Coal Gasification Environments, Materials for Coal Gasification, W.T. Bakker, S. Dapkunas and V. Hill Eds. (ASM International, Metals Park, Ohio, 1988) pp. 51-60.

[27] PERKIns R.A., MARSH D.L., SAROSIEK A.M. and BAKKer W.T., Downtime Corrosion in Syngas Coolers of Entrained Slagging Gasifiers, EPRI Report AP-5966 (Electric Power Research Institute, Palo Alto, California, 1988).

[28] KRAUSE H.H., Corrosion by Chlorine in Waste-Fueled Boilers, Incinerating Municipal and Industrial Waste, R.W. Bryers Ed. (Hemisphere Publishing Corporation, New York, N.Y., 1991) pp. 145-159.

[29] HANCOCK P., Proc. 1974 Conf. on Gas Turbine Materials in the Marine Environment, J.W. Fairbanks and I. Machlin Eds., Metals and Ceramics Information Center Report MCIC-75-27 (Battelle Columbus Laboratories, Columbus, Ohio, 1974) pp. 225-236. 